\title{
Possible effect of extreme solar energetic particle events of September-October 1989 on polar stratospheric aerosols: a case study
}

\author{
I. A. Mironova ${ }^{1}$ and I. G. Usoskin ${ }^{2}$ \\ ${ }^{1}$ Institute of Physics, St. Petersburg State University, St. Petersburg, Russia \\ ${ }^{2}$ Sodankylä Geophysical Observatory (Oulu unit and Dept. of Physics), University of Oulu, Finland \\ Correspondence to: I. A. Mironova (mironova@geo.phys.spbu.ru)
}

Received: 18 December 2012 - Published in Atmos. Chem. Phys. Discuss.: 27 February 2013

Revised: 6 June 2013 - Accepted: 14 July 2013 - Published: 2 September 2013

\begin{abstract}
The main ionization source of the middle and low Earth's atmosphere is related to energetic particles coming from outer space. Usually it is ionization from cosmic rays that is always present in the atmosphere. But in a case of a very strong solar eruption, some solar energetic particles (SEPs) can reach middle/low atmosphere increasing the ionization rate up to some orders of magnitude at polar latitudes. We continue investigating such a special class of solar events and their possible applications for natural variations of the aerosol content. After the case study of the extreme SEP event of January 2005 and its possible effect upon polar stratospheric aerosols, here we analyze atmospheric applications of the sequence of several events that took place over autumn 1989. Using aerosol data obtained over polar regions from two satellites with space-borne optical instruments SAGE II and SAM II that were operating during SeptemberOctober 1989, we found that an extreme major SEP event might have led to formation of new particles and/or growth of preexisting ultrafine particles in the polar stratospheric region. However, the effect of the additional ambient air ionization on the aerosol formation is minor, in comparison with temperature effect, and can take place only in the cold polar atmospheric conditions. The extra aerosol mass formed under the temperature effect allows attributing most of the changes to the "ion-aerosol clear sky mechanism".
\end{abstract}

\section{Introduction}

Natural variability of the outer space factors, in particular cosmic ray fluctuations, is important for the terrestrial environment. Cosmic rays produce a direct effect on the Earth's atmosphere via ionization of the ambient air and form the main source of the atmospheric ionization for the lower and middle atmosphere (Bazilevskaya et al., 2008). There are some indications that it may affect properties of the atmospheric aerosols (Kazil et al., 2008; Mironova et al., 2008, 2012) and possibly even cloud formation (Carslaw et al., 2002; Tinsley, 2008), which may be crucially important as an indirect factor affecting the climate. However, it is still a subject of intensive debates (Kulmala et al., 2010; Usoskin et al., 2010b; Calogovic et al., 2010). Statistical correlation studies are inconclusive and lead to contradictory results largely because the contemporary fast expansion of the anthropogenic factor makes it difficult to study the natural variability of the terrestrial system, including the solar factor, by means of statistical/phenomenological methods. Direct laboratory and in situ experiments (Kulmala et al., 2010; Kirkby et al., 2011; Enghoff et al., 2011) suggest that enhanced ionization may lead to aerosol particle formation in the realistic conditions, but this effect is small. There are also some global aerosol microphysics model studies testing the sensitivity of cloud condensation nuclei (CCN) concentration to the changes in nucleation that might occur due to changes in cosmic rays. Such modeling approaches have been done by Pierce and Adams (2009); Kazil et al. (2012); Snow-Kropla et al. (2011); Dunne et al. (2012); Yu et al. (2012). 
In spite of the wide interest of the science community to the topic of aerosol formation under the influence of cosmic ray induced ionization in the atmosphere, most of models and experimental works were done for the troposphere and/or boundary layers conditions. On the other hand, the stratospheric effect is not properly studied, although the maximum cosmic ray induced ionization rate in the atmosphere corresponds exactly in the region of the polar stratosphere (Bazilevskaya et al., 2008).

Here we continue studying, from atmospherical point of view, major solar energetic particle (SEP) events occurring in relation to solar eruptive phenomena, when the flux of energetic particles can penetrate down to the lower level of atmosphere and can be detectable by ground-based neutron monitors. The energies of such solar particles are below the energies of galactic cosmic rays (GCRs). And these sporadic events produce additional ionization of the atmosphere that exceeds the background ionization level due to GCRs by several orders of magnitude in the polar stratosphere (Usoskin et al., 2011).

While the effect caused by SEP events in the upper atmosphere is more or less known (Randall et al., 2007; Seppälä et al., 2008; Egorova et al., 2011; Rozanov et al., 2012), its possible influence on the lower atmosphere is still unclear. Previous phenomenological studies (Mironova et al., 2008, 2012) yielded that there is a small, marginally detectable effect of an extreme SEP (e.g., such as the one of 20 January 2005) on the aerosol particles in the lower-middle polar stratosphere during stable winter/summer conditions. However, an appropriate model able to explain the observed features is still missing. Here we study the series of SEP events in autumn 1989, which was among the largest events, aiming at providing an assessment of the possible atmospheric effect of energetic particles on stratospheric-tropospheric aerosols.

We focus on short-time sporadic solar eruptive events, which can help in separating the cosmic ray effect because of its sharp temporal (duration of hours-days) and spatial (polar region) localization. It is a step forward toward a realistic consideration of the effect for developing an empirical quantitative model, able to parameterize the atmospheric changes (ionization rate, aerosols properties, etc.) for specific conditions, such as the flux of cosmic rays of galactic/solar origin, season and location.

\section{Data for the time interval of September-October 1989}

For our analysis we have chosen the time interval of September-October 1989, where a series of major SEP events, recorded also as ground level enhancements (GLEs) of ground-based neutron monitors, took place. These SEP events were among the strongest ones in the 22nd solar cycle (Duldig et al., 1993; Lovell et al., 1998). On the other hand, the atmospheric conditions were monitored by several spaceborne instruments during that period, making a detailed case study possible. While the chemistry of the upper atmosphere is known to be greatly affected by the SEP events in autumn of 1989 (Vitt et al., 2000; Verronen et al., 2002), a direct detailed analysis of the low and middle atmosphere data has not been done previously.

\subsection{Solar energetic particles and cosmic ray induced ionization}

As an index of cosmic ray variability, we show in Fig. 1 (upper panel) the count rate of the polar Oulu neutron monitor. One can see that four GLE/SEP events took place during September-October 1989: the strongest event of the series occurred on September 29th (day of year, DOY 272); followed by a series of moderate events of 19, 22 and 24 October (DOY 292, 295 and 297, respectively). These events are indicated by vertical lines at this and forthcoming figures. The lower panel of Fig. 1 depicts the corresponding cosmic ray induced ionization (CRII) of the atmosphere, calculated using the CRAC : CRII model (Usoskin and Kovaltsov, 2006; Usoskin et al., 2010a). One can see that the ionization effect of the SEP events penetrated down to about $10 \mathrm{~km}$ for the greatest of the analyzed events of DOY 272, to about $15 \mathrm{~km}$ for moderate events of DOY 292, and 297 and was hardly noticeable below $18 \mathrm{~km}$ for the weak event of DOY 295. Atmospheric ionization during these events has been discussed in Usoskin et al. (2011). We note that GLEs of autumn 1989 were weaker than those of January 2005. However cosmic ray induced ionization of the stratosphere over polar regions on 29 September 1989 was of the same order of magnitude as it was on 20 January 2005 (Usoskin et al., 2011). This leads us to concentrate our analysis on the September event but also taking into account the other GLEs taking place in autumn 1989.

\subsection{Remote sensing of the atmosphere during September-October 1989}

During autumn 1989 two satellites provided vertical profiles of aerosol extinctions over polar regions. One of them was a satellite with SAGE II apparatus giving retrieval information on aerosol extinction at the $1020,525,453$, and 385 nanometer wavelengths, the aerosol surface area density and the effective radius. Another satellite had SAM II experiment, also giving information about the aerosol extinction at only one wavelength of $1000 \mathrm{~nm}$. Let us consider both satellites separately with their experiments and their capabilities of taking data for our investigation.

\subsection{Latitudinal coverage of SAGE II}

The Stratospheric Aerosol and Gas Experiment (SAGE) II data and all supported information were taken from the site (http://www-sage2.larc.nasa.gov/). 

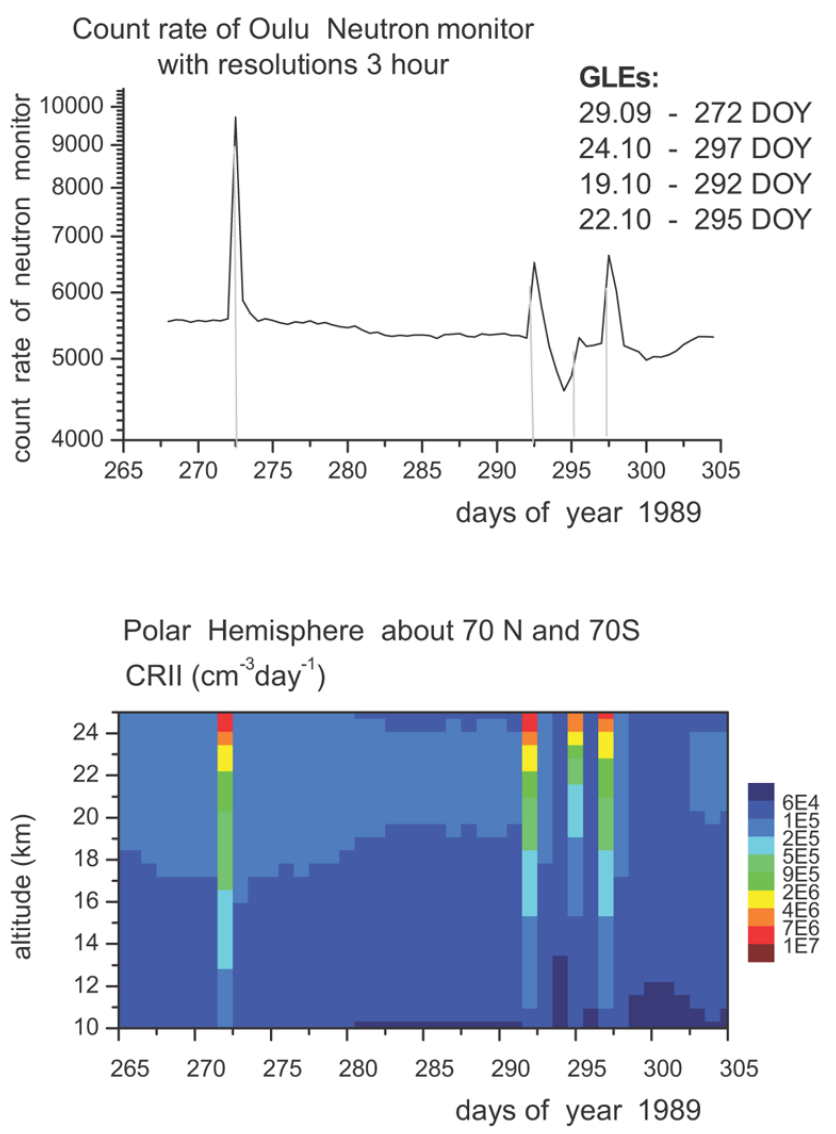

Fig. 1. Cosmic rays and atmospheric ionization variability during the period of September-October 1989. Upper panel: daily averaged count rate of the Oulu polar neutron monitor, with four GLE/SEP events indicated by the vertical lines. Lower panel: calculated corresponding cosmic ray induced ionization rate in the polar atmosphere. Logarithmic color scale is shown on the right panel.

The SAGE II was launched aboard the Earth Radiation Budget Satellite in October 1984. The SAGE II instrument used the solar occultation technique to measure attenuated solar radiation through the Earth's limb in the channels centered at wavelengths ranging from 385 to $1020 \mathrm{~nm}$. The exoatmospheric solar irradiance is also measured in each channel during each event for the use as a reference in determining limb transmittances. The instrument provides high quality measurements of ozone, nitrogen dioxide, water vapor, and multi-wavelength aerosol extinction from the midtroposphere to as high as the lower mesosphere. The aerosol data contain profiles of aerosol extinction at 1020, 525, 453, and $385 \mathrm{~nm}$, the aerosol surface area density and the effective radius at the vertical resolution of $0.5 \mathrm{~km}$.

Latitudinal coverage of the satellite with the SAGE II instrument, during the end of September till the end of October 1989, is presented in Fig. $2 b$ and d. One can see that during that period SAGE II could cover all latitudes from the Equator to polar areas in both hemispheres. Since addi-
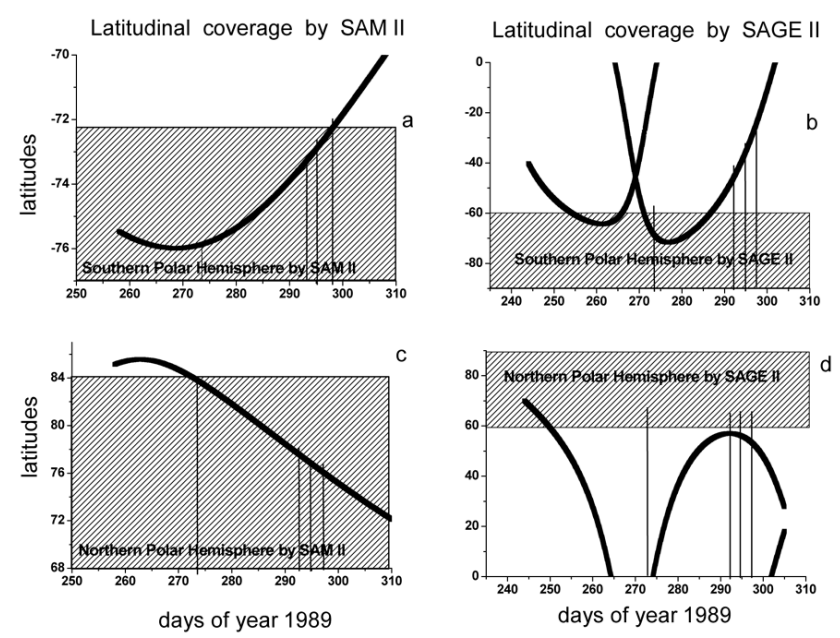

Fig. 2. Latitude distance of SAM II ((a) and (c)) and SAGE II ((b) and (d)) during September-October 1989. The days of GLEs marked by lines. (a) and (b): latitudinal coverage of the satellites and operation of the instruments during each sunrise and sunset measurement over Southern Hemisphere. (c) and (d): the same as for upper panel, but over Northern Hemisphere.

tional ionization effects from a GLE event will be noticed only in the polar atmosphere, we need to use for our investigation only data obtained from polar regions. In Fig. 2 these regions are shown by dashed boxes. Unfortunately in spite of the extensive data coverage of the Northern Hemisphere (see Fig. 2d), we cannot use it for our analysis since the SAGE II did not cover polar regions during the period of time under investigation. As one can see in Fig. $2 b$ only during the first GLE on DOY 272, SAGE II could cover Southern Hemisphere polar regions, which helps us in our study.

\subsection{Latitudinal coverage of SAM II}

The Stratospheric Aerosol Measurement (SAM) II data and all the supported information were taken from the site of Atmospheric Science Data Center (http://eosweb.larc.nasa.gov/).

The SAM II instrument, aboard the Earth-orbiting Nimbus-7 spacecraft, was designed to measure solar irradiance attenuated by aerosol particles in the Arctic and Antarctic stratosphere. The scientific objective of the SAM II experiment was to develop a stratospheric aerosol database for the polar regions by measuring and mapping vertical profiles of the atmospheric extinction due to aerosols. The measurement technique is solar occultation. The latitude of the measurements was slowly changed with the season by one to two degrees per week. Therefore, for our short period study of about one month the latitudinal changes could not play a big role in our case in contrast to the SAGE II measurements. The operations of SAM II took place in the latitude regions of about $70^{\circ}$ for both polar hemispheres. Figure $2 \mathrm{a}$ and c show coverage by SAM II. Here one can see slow latitudinal changes 

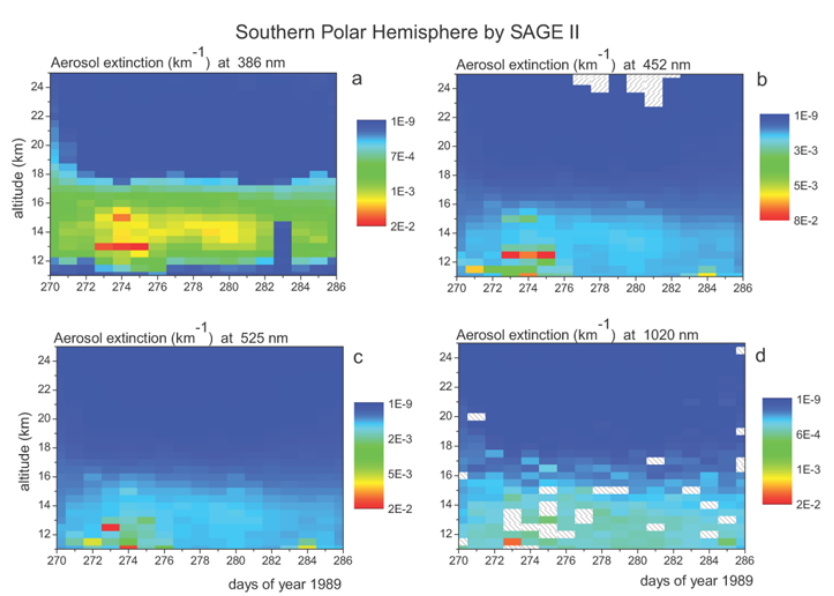

Fig. 3. SAGE II aerosol optical properties such as aerosol extinctions at four wavelengths $1020 \mathrm{~nm}, 525 \mathrm{~nm}, 453 \mathrm{~nm}$ and $386 \mathrm{~nm}$ for the polar Southern Hemisphere.

over both hemispheres. The SAM II data obtained from polar regions are shown by dashed boxes in Fig. 2a and c. Unfortunately SAM II provides aerosol extinction data only at one wavelength of $1000 \mathrm{~nm}$.

As a sub-conclusion on the satellites data over autumn 1998, we notice that we can use SAGE II data (see Fig. 2b) only for the polar Southern Hemisphere and only for an analysis of the largest GLE of 29 September 1989. And SAM II aerosol information can be taken only at $1000 \mathrm{~nm}$ wavelength, but for both polar hemispheres for all the GLEs over the end of September till the end of October 1989 (see Fig. 2a and c).

\section{Aerosol properties associated with the GLE event}

Ions play an important role in the atmospherical processes. However up to now the role of ions in the aerosol formation is still not clear. One of the proposed link mechanisms (Carslaw et al., 2002) is the so-called "the ion-aerosol clearair mechanism" based on the presence of ions that enhance formation and early growth of aerosol particles in the atmosphere so that such fractions may eventually grow to cloud condensation nuclei $(\mathrm{CCN})$. An additional ionization source in the polar atmosphere can help to test this possible mechanism of aerosol formation in the real cold atmosphere. Such additional ionization sources can be short-time sporadic solar eruptive events, which can help in separating the effect of cosmic rays because of their sharp temporal (duration of hours-days) and spatial (polar region) localization. An analysis of vertical aerosol profiles during such sporadic events shall show the exact altitudinal regions where some changes connected with investigated increasing of ionization rate and numbers of ions in the atmosphere take place.

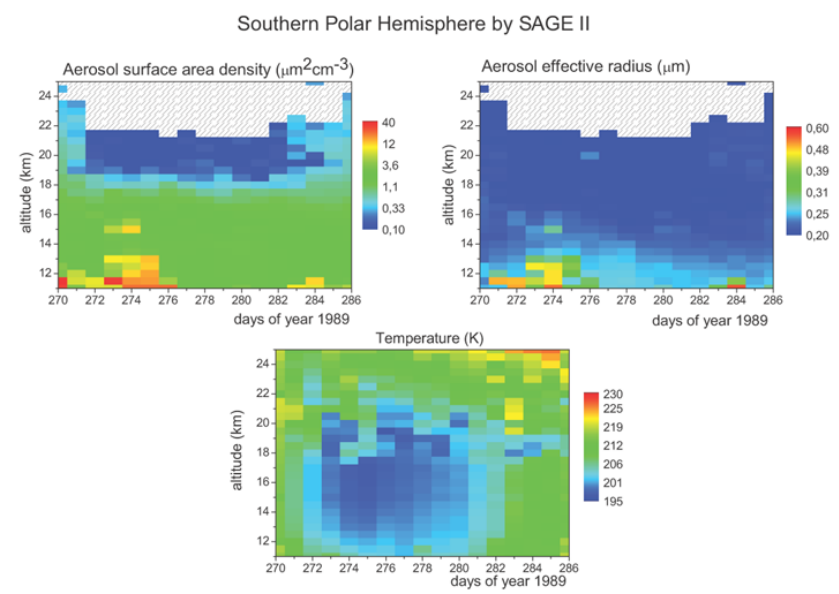

Fig. 4. Aerosol microphysical properties and temperature obtained by SAGE II data sets. Logarithmic color scale is shown on the right of each panel. Upper panel: variations of surface area density and effective aerosol radius. Lower panel: variations of temperature.

\subsection{Aerosol properties observed by SAGE II}

Altitudinal and temporal 2-D variations of the optical properties of aerosols are shown in Fig. 3. Altitudinal and temporal 2-D variations of aerosol microphysical properties such as effective aerosol radius and aerosol surface area density are shown in the upper panels of Fig. 4. Variations of the temperature for the southern polar atmosphere for the period of time under investigation can be also seen in the lower panel of Fig. 4. All the SAGE II data used in the present study are zonal averages over the appropriate longitudes in the polar region.

As mentioned in Sect. 2.2 the data from SAGE II can be used for finding atmospheric effects only from the first GLE event that took place on DOY 272. And unfortunately this data cannot be compared with the SAGE II data obtained in the Northern Hemisphere. Figures 3 and 4, where altitudinal and temporal variations of aerosol optical as well as aerosol microphysical properties are shown, clearly indicate an increase of aerosol parameters after the GLE event. In Fig. 3 one can see that over the altitudinal range of about $13 \mathrm{~km}$, after DOY 272, the aerosol extinction in the visible wavelengths increased by an order of magnitude in comparison with previous days. However, this effect is less notable for the aerosol extinction at the longest wavelengths. The variations of aerosol optical parameters are confirmed by microphysical changes of aerosol properties. In Fig. 4 (upper panel) one can also see a notable increase of the aerosol surface area density (SAD) on the second day after the GLE and subtle changes in the aerosol effective radius. The surface area density increases from about $\sim 3$ to $\sim 12-20 \mu \mathrm{m}^{2} \mathrm{~cm}^{-3}$ at altitudes $12-13 \mathrm{~km}$ around DOY 274 . The effective radius doubles from about $0.25 \mu \mathrm{m}$ to $0.5 \mu \mathrm{m}$. For fixed aerosol number, the surface area scales with the square of the radius, 
so a jump in surface area density from 3 to $12 \mu \mathrm{m}^{2} \mathrm{~cm}^{-3}$ (a $4 \times$ increase) can be explained by the doubling of the radius of the particles without any increase in aerosol number (for a fixed distribution shape). There would, however, have to be an increase in aerosol mass to make these particles larger. On the other hand, a jump in surface area density from 3 to $20 \mu^{2} \mathrm{~cm}^{-3}$ could not be explained by holding the number fixed (for a fixed distribution shape, some additional aerosol number would be necessary), but regardless there would need to be an increase in total aerosol mass.

If the "ion-aerosol clear sky" mechanism were acting alone, the aerosol mass would be fixed. An increase in nucleation due to the increase in ions would lead to a decrease in the effective radius because the aerosol mass would be distributed across more particles, so they would all be smaller (on average). Thus, the addition of aerosol mass here could possibly be due to the decrease in temperature if this caused additional material to condense (J. R. Pierce, personal communication, 2013).

The lower panel of Fig. 4 shows altitudinal and temporal temperature changes. Here a decrease of temperature down to $195 \mathrm{~K}$ is visible after DOY 272 over the altitude range from 12 to $20 \mathrm{~km}$. The changes of the temperature might affect the aerosol particles, and cooling will lead to formation of polar stratospheric clouds. Aerosol particles shall grow when the temperature is low enough (in our case $195 \mathrm{~K}$ ) and that will be seen in the increasing of SAD and ratable in the increasing of effective aerosol radius.

These results, discussed above, let us propose a scenario of the changes of aerosol properties that take place at the same time in our case. One is the homogenous theory of the new aerosol particle formation after a decrease of the temperature and another scenario is related to additional ionization that also can lead to the notable effect from the exact day of GLE.

In addition, the variability of microphysical aerosol parameters such as the effective aerosol radius and aerosol surface area density was investigated for typical atmospheric conditions such as those during September 1989 in the polar Southern Hemisphere. In this study we check periods during the years 1986-1990, for the background variability of the investigated parameters that were not affected by El Chichón (1982) and Mount Pinatubo (1991) volcanic eruptions. As a summary we can say that the aerosol surface area density, in the sense of the variability, is a more sensitive parameter to variations of the temperature below $200 \mathrm{~K}$ than the aerosol effective radius is. We note that the uncertainties of the stratospheric aerosol properties measured by SAGE II during non-volcanic periods were investigated by Thomason et al. (2008) in great detail. Here it is mentioned that the maximum range of reasonable SAD values around the current operational values is of the order of a factor of 2 for non-volcanic conditions. In the case of our investigation, we observe increases of SAD of the order of a factor of 4 on the day after GLE in September 1989, which is beyond the expected uncertainties. Thomason et al. (2008) have also noted

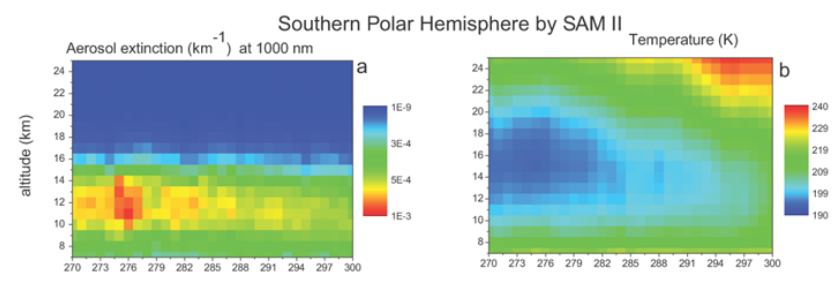

Northern Polar Hemisphere by SAM II

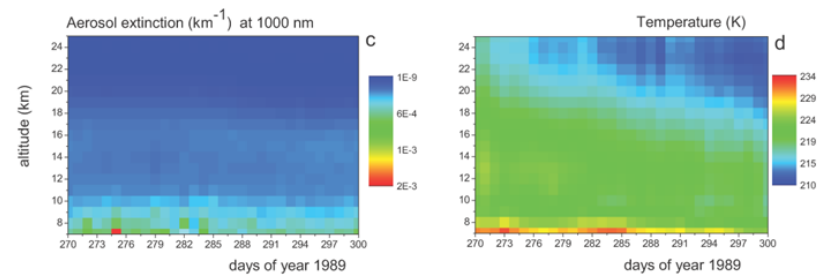

Fig. 5. Variations of the aerosol extinction at wavelength of $1000 \mathrm{~nm}$ and the temperature over polar hemispheres during the end of September till the end of October 1989. Upper panel: variations of atmospheric parameters over the Southern Hemisphere. Lower panel: the same but for the Northern Hemisphere. Logarithmic color scale of temperature changes is shown on the right of each panel.

that SAD may not provide reasonable limits in regions of the stratosphere where strong particle nucleation occurs such as the polar winter middle stratosphere since number densities may be considerably larger than those considered here though the SAGE II-measured extinctions remain valid.

\subsection{Aerosol properties observed by SAM II}

Exploitation of the data from the SAM II instrument gives us a good opportunity to compare some results obtained by SAGE II over the Southern Hemisphere and also to have additional information about behavior of aerosols and temperature over the northern polar regions during the period of time needed for investigation. However here we also need to reiterate that the data from SAM II can be taken only at $1000 \mathrm{~nm}$, and it is hard to do an approximation of microphysical changes of aerosol particles as well as of the optical properties in the visible range of wavelengths. Nevertheless after analysis of the SAM II data sets, we will be able to see what happened in both the polar Southern Hemisphere and Northern Hemisphere for all the GLEs over SeptemberOctober 1989. Here we also used SAM II data that have been zonally averaged over all appropriate longitudes in both polar regions.

Altitudinal and temporal 2-D variations of the aerosol extinction at wavelength of $1000 \mathrm{~nm}$, and the temperature for the Southern Hemisphere and the Northern Hemisphere are presented in Fig. 5. In the upper panels of Fig. 5, variations of aerosol parameters and the temperature changes are shown over the investigated period of time for the Southern Hemisphere. The lower panels of Fig. 5 show behavior of aerosols 
and temperature changes over the investigated period of time for the Northern Hemisphere.

Let us begin our analysis with the SAM II aerosol data over the Southern Hemisphere. Here, in Fig. 5a, one can see a small increase of the aerosol extinction after DOY 272, which is in good agreement with altitudinal and temporal variations of the aerosol extinction obtained by SAGE II (Fig. 3d). However changes of temperature (Fig. 5b) began much earlier, as shown in Fig. 4 (lower panel). The decrease of the temperature down to $190 \mathrm{~K}$ over altitudes at about $11-20 \mathrm{~km}$ began in the SAM II data from DOY 270. However SAGE II data show a decrease of the temperature down to $195 \mathrm{~K}$ over the same altitudes from DOY 272 . No parallel changes are observed in the aerosol optical properties recorded by the SAGE II and the SAM II tools at the comparable wavelength of about $1000 \mathrm{~nm}$ (SAGE II $-1020 \mathrm{~nm}$ and SAM II $-1000 \mathrm{~nm}$ ). In Fig. 5a, in the altitude range of about $10-15 \mathrm{~km}$, one can see a small increase of aerosol extinction on DOY 275. Nevertheless Fig. 3d, where the aerosol extinction at $1020 \mathrm{~nm}$ detected by SAGE II is presented, shows also a weak increase of aerosol extinction on DOY 273. However at other wavelengths of SAGE II (Fig. 3a-c), one can see some aerosol optical changes, which can be logically confirmed by the data of SAM II (see Figure 5a).

In spite of these differences in the temperatures and the aerosol extinctions at wavelength of about $1000 \mathrm{~nm}$, recorded by the SAGE II and the SAM II tools, we can confirm that both instruments show formation and/or growth of the aerosol particles after DOY 272.

The situation is completely different for the Northern Hemisphere in comparison with Southern Hemisphere (see lower panel of Fig. 5). No notable changes occur during the investigated period of time. However the temperature is also much higher that it can be observed in the Southern Hemisphere.

\section{Conclusions}

A detailed analysis of the behavior of aerosol particles and their dependence on temperature variations and increase of ionization over the end of September till the end of October 1989 for both polar hemispheres is presented. Here we found a minor possible effect from the additional ionization coming from one of the biggest GLE events in September 1989. The effect was observed by SAGE II and SAM II in the polar Southern Hemisphere.

We conclude that the present results show variations of the aerosol optical and microphysical parameters (in the cold polar stratosphere) that are similar to the aerosol variations detected after the GLE in January 2005 (Mironova et al., 2012). The recognized effect, during these two GLEs (20 January 2005 and 29 September 1989), is found at the same altitude range of 10-20 km. However, during September 1989 the effect penetrated deeper into the lower stratosphere. No effects were found at other altitudes. No observ- able effect in formation and/or growth of preexisting ultrafine particles in the polar stratospheric region was found for the weaker GLEs during October 1998. The maximum effect was observed some days after the GLE in September 1989. Based on the present investigation we conclude that ionization plays a role in addition to the temperature in formation of polar stratospheric clouds. Nevertheless it is difficult to isolate quantitatively the ion-aerosol clear sky mechanism (which generates additional aerosol numbers) from the additional aerosol mass that occurs.

In the wintertime polar Southern Hemisphere (Antarctic), air is strongly controlled by the polar vortex, resulting in a cold environment and in the isolation of stratospheric gases and aerosol. The period of time from June to October is associated in Antarctic region with formation of polar stratospheric clouds (PSCs). It is well known that the temperature change can affect the aerosol properties, and cooling in the stratosphere can lead to Antarctic PSC formation. In turn PSCs are involved in formation of the ozone hole. PSCs provide surfaces upon which heterogeneous chemical reactions take place, and these reactions lead to the production of free radicals of chlorine in the polar stratosphere, which directly destroy the ozone level. The ozone hole is bigger for larger surface area density of the PSCs.

Here it is necessary to notice that in both cases of GLEs (20 January 2005 and 29 September 1989) it was found that the extra aerosol mass occurs and attributes most of the changes to the ion-aerosol clear sky mechanism.

Taking into account that the obtained effect was found in the region with sufficiently low temperature where formation of polar stratospheric clouds is possible, which is in turn critical for the development of polar ozone loss, we cannot exclude a possibility that an increase of the cosmic ray induced ionization rate can lead to formation of an aerosol layer, which can influence the microphysical properties of PSCs. However this effect should be investigated by a detailed model study, which is beyond the scope of this work.

Acknowledgements. The SAGE II data are provided by the NASA Langley Research Center (NASA-LaRC) and the NASA Langley Radiation and Aerosols Branch. The SAM II data are provided also by the NASA Langley Research Center and obtained from the Langley DAAC User and Data Services Office. Data of Oulu neutron monitor are available at http://cosmicrays.oulu.fi. Support from the Academy of Finland and Suomalainen Tiedeakatemia is acknowledged. I. A. Mironova acknowledges support from RFBR (grant N13-05-01063A). The present work was performed in relation with the following international programs: CAWSES-II and COST ES0803 and ES1005. Part of this work was supported by the COST Action ES1005 "Toward a more complete assessment of the impact of solar variability on the Earth's climate". The authors acknowledge useful discussions within the ISSI Team on Study of Cosmic Ray Influence upon Atmospheric Processes. The authors are grateful to the reviewers and J. R. Pierce for their valuable comments that improved the manuscript.

Edited by: W. Ward 


\section{References}

Bazilevskaya, G. A., Usoskin, I. G., Flückiger, E. O., Harrison, R. G., Desorgher, L., Bütikofer, R., Krainev, M. B., Makhmutov, V. S., Stozhkov, Y. I., Svirzhevskaya, A. K., Svirzhevsky, N. S., and Kovaltsov, G. A.: Cosmic ray induced ion production in the atmosphere, Space Sci. Rev., 137, 149-173, doi:10.1007/s11214008-9339-y, 2008.

Calogovic, J., Albert, C., Arnold, F., Beer, J., Desorgher, L., and Flueckiger, E. O.: Sudden cosmic ray decreases: No change of global cloud cover, Geophys. Res. Lett., 370, L03802, doi:10.1029/2009GL041327, 2010.

Carslaw, K. S., Harrison, R. G., and Kirkby, J.: Cosmic Rays, Clouds, and Climate, Science, 298, 1732-1737, doi:10.1126/science.1076964, 2002.

Duldig, M. L., Cramp, J. L., Humble, J. E., Smart, D. F., Shea, M. A., Bieber, J. W., Evenson, P., Fenton, K. B., Fenton, A. G., and Bendoricchio, M. B. M.: The Ground Level Enhancements of 1989SEP29 and 1989OCT22, Proc. Astronom. Soc. Australia, 10, 211-217, 1993.

Dunne, E. M., Lee, L. A., Reddington, C. L., and Carslaw, K. S.: No statistically significant effect of a short-term decrease in the nucleation rate on atmospheric aerosols, Atmos. Chem. Phys., 12, 11573-11587, doi:10.5194/acp-12-11573-2012, 2012.

Egorova, T., Rozanov, E., Ozolin, Y., Shapiro, A., Calisto, M., Peter, T., and Schmutz, W.: The atmospheric effects of October 2003 solar proton event simulated with the chemistryclimate model SOCOL using complete and parameterized ion chemistry, J. Atmos. Solar-Terr. Phys., 73, 356-365, doi:10.1016/j.jastp.2010.01.009, 2011.

Enghoff, M. B., Pedersen, J. O. P., Uggerhøj, U. I., Paling, S. M., and Svensmark, H.: Aerosol nucleation induced by a high energy particle beam, Geophys. Res. Lett., 380, L09805, doi:10.1029/2011GL047036, 2011.

Kazil, J., Harrison, R. G., and Lovejoy, E. R.: Tropospheric New Particle Formation and the Role of Ions, Space Sci. Rev., 137, 241-255, doi:10.1007/s11214-008-9388-2, 2008.

Kazil, J., Zhang, K., Stier, P., Feichter, J., Lohmann, U., and O'Brien, K.: The present-day decadal solar cycle modulation of Earth's radiative forcing via charged $\mathrm{H}_{2} \mathrm{SO}_{4} / \mathrm{H}_{2} \mathrm{O}$ aerosol nucleation, 39, L02805, doi:10.1029/2011GL050058, 2012.

Kirkby, J., Curtius, J., Almeida, J., Dunne, E., Duplissy, J., Ehrhart, S., Franchin, A., Gagne, S., Ickes, L., Kurten, A., Kupc, A., Metzger, A., Riccobono, F., Rondo, L., Schobesberger, S., Tsagkogeorgas, G., Wimmer, D., Amorim, A., Bianchi, F., Breitenlechner, M., David, A., Dommen, J., Downard, A., Ehn, M., Flagan, R. C., Haider, S., Hansel, A., Hauser, D., Jud, W., Junninen, H., Kreissl, F., Kvashin, A., Laaksonen, A., Lehtipalo, K., Lima, J., Lovejoy, E. R., Makhmutov, V., Mathot, S., Mikkila, J., Minginette, P., Mogo, S., Nieminen, T., Onnela, A., Pereira, P., Petaja, T., Schnitzhofer, R., Seinfeld, J. H., Sipila, M., Stozhkov, Y., Stratmann, F., Tome, A., Vanhanen, J., Viisanen, Y., Vrtala, A., Wagner, P. E., Walther, H., Weingartner, E., Wex, H., Winkler, P. M., Carslaw, K. S., Worsnop, D. R., Baltensperger, U., and Kulmala, M.: Role of sulphuric acid, ammonia and galactic cosmic rays in atmospheric aerosol nucleation, Nature, 476, 429-433, doi:10.1038/nature10343, http: //dx.doi.org/10.1038/nature10343, 2011.

Kulmala, M., Riipinen, I., Nieminen, T., Hulkkonen, M., Sogacheva, L., Manninen, H. E., Paasonen, P., Petäjä, T., Dal Maso,
M., Aalto, P. P., Viljanen, A., Usoskin, I., Vainio, R., Mirme, S., Mirme, A., Minikin, A., Petzold, A., Hõrrak, U., Plaß-Dülmer, C., Birmili, W., and Kerminen, V.-M.: Atmospheric data over a solar cycle: no connection between galactic cosmic rays and new particle formation, Atmos. Chem. Phys., 10, 1885-1898, doi:10.5194/acp-10-1885-2010, 2010.

Lovell, J. L., Duldig, M. L., and Humble, J. E.: An extended analysis of the September 1989 cosmic ray ground level enhancement, J. Geophys. Res., 103, 23733-23742, doi:10.1029/98JA02100, 1998.

Mironova, I. A., Desorgher, L., Usoskin, I. G., Flückiger, E. O., and Bütikofer, R.: Variations of aerosol optical properties during the extreme solar event in January 2005, Geophys. Res. Lett., 35, L18610, doi:10.1029/2008GL035120, 2008.

Mironova, I. A., Usoskin, I. G., Kovaltsov, G. A., and Petelina, S. V.: Possible effect of extreme solar energetic particle event of 20 January 2005 on polar stratospheric aerosols: direct observational evidence, Atmos. Chem. Phys., 12, 769-778, doi:10.5194/acp12-769-2012, 2012.

Pierce, J. R. and Adams, P. J.: Can cosmic rays affect cloud condensation nuclei by altering new particle formation rates?, Geophys. Res. Lett., 360, L09820, doi:10.1029/2009GL037946, 2009.

Randall, C. E., Harvey, V. L., Singleton, C. S., Bailey, S. M., Bernath, P. F., Codrescu, M., Nakajima, H., and Russell, J. M.: Energetic particle precipitation effects on the Southern Hemisphere stratosphere in 1992-2005, J. Geophys. Res., 112, D08308, 2007.

Rozanov, E., Calisto, M., Egorova, T., Peter, T., and Schmutz, W.: The influence of the precipitating energetic particles on atmospheric chemistry and climate, Surv. Geophys., 33, 483-501, 2012.

Seppälä, A., Clilverd, M. A., Rodger, C. J., Verronen, P. T., and Turunen, E.: The effects of hard-spectra solar proton events on the middle atmosphere, J. Geophys. Res., 113, A11311, doi:10.1029/2008JA013517, 2008.

Snow-Kropla, E. J., Pierce, J. R., Westervelt, D. M., and Trivitayanurak, W.: Cosmic rays, aerosol formation and cloudcondensation nuclei: sensitivities to model uncertainties, Atmos. Chem. Phys., 11, 4001-4013, doi:10.5194/acp-11-4001-2011, 2011.

Thomason, L. W., Burton, S. P., Luo, B.-P., and Peter, T.: SAGE II measurements of stratospheric aerosol properties at non-volcanic levels, Atmos. Chem. Phys., 8, 983-995, doi:10.5194/acp-8-9832008, 2008.

Tinsley, B. A.: The global atmospheric electric circuit and its effects on cloud microphysics, Rep. Prog. Phys., 71, 066801, doi:10.1088/0034-4885/71/6/066801, 2008.

Usoskin, I. G. and Kovaltsov, G. A.: Cosmic ray induced ionization in the atmosphere: Full modeling and practical applications, J. Geophys. Res., 111, D21206, doi:10.1029/2006JD007150, 2006.

Usoskin, I. G., Kovaltsov, G. A., and Mironova, I. A.: Cosmic ray induced ionization model CRAC:CRII: An extension to the upper atmosphere, J. Geophys. Res., 115, D10302, 2010 a.

Usoskin, I. G., Mironova, I. A., Korte, M., and Kovaltsov, G. A.: Regional millennial trend in the cosmic ray induced ionization of the troposphere, J. Atmosph. Sol.-Terr. Phys., 72, 19-25, 2010 b.

Usoskin, I. G., Kovaltsov, G. A., Mironova, I. A., Tylka, A. J., and Dietrich, W. F.: Ionization effect of solar particle GLE events in low and middle atmosphere, Atmos. Chem. Phys., 11, 1979- 
1988, doi:10.5194/acp-11-1979-2011, 2011.

Verronen, P. T., Turunen, E., Ulich, T., and Kyrölä, E.: Modelling the effects of the October 1989 solar proton event on mesospheric odd nitrogen using a detailed ion and neutral chemistry model, Ann. Geophys., 20, 1967-1976, doi:10.5194/angeo-201967-2002, 2002.

Vitt, F., Armstrong, T., Cravens, T., Dreschhoff, A., Jackman, C., and Laied, C.: Computed contributions to odd nitrogen concentrations in the Earth's polar middle atmosphere by energetic charged particles., J. Atmos. Terr. Phys., 62, 669-683, 2000.
Yu, F., Luo, G., Liu, X., Easter, R. C., Ma, X., and Ghan, S. J.: Indirect radiative forcing by ion-mediated nucleation of aerosol, Atmos. Chem. Phys., 12, 11451-11463, doi:10.5194/acp-1211451-2012, 2012. 